Elsevier required licence: (c) $<2018>$. This manuscript version is made available under the CC-BY-NC-ND 4.0 license http://creativecommons.org/licenses/bync-nd/4.0/ 


\section{Differential effects of hepatic cirrhosis on the intrinsic clearances of sorafenib and imatinib by CYPs in human liver}

Michael Murray, ${ }^{\mathrm{a}, *}$ Tina B. Gillani, ${ }^{\mathrm{a}}$ Sussan Ghassabian, ${ }^{\mathrm{a}}$ Robert J Edwards, ${ }^{\mathrm{b}}$ and Tristan Rawling $^{\mathrm{c}}$

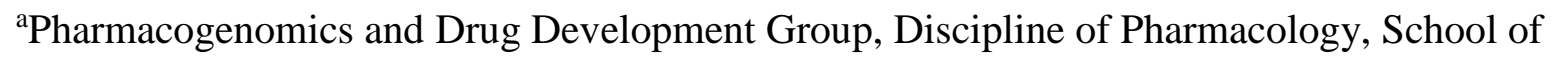
Medical Sciences, Sydney Medical School, University of Sydney, NSW 2006, AUSTRALIA, ${ }^{\mathrm{b}}$ Centre for Pharmacology and Therapeutics, Division of Experimental Medicine, Imperial College London, Hammersmith Campus, UNITED KINGDOM, and 'School of Mathematical and Physical Sciences, Faculty of Science, University of Technology Sydney, Ultimo, New South Wales, 2007, AUSTRALIA

*Address for correspondence: Dr Michael Murray,

Discipline of Pharmacology,

University of Sydney,

NSW 2006,

AUSTRALIA

Tel: (61-2)-9036-3259

Fax: (61-2)-9351-4447

email: michael.murray@sydney.edu.au

Running title: $\quad$ CYP3A4 and sorafenib biotransformation in liver disease 


\section{Abstract}

The tyrosine kinase inhibitors sorafenib and imatinib are important in the treatment of a range of cancers but adverse effects in some patients necessitate dosage modifications. CYP3A4 has a major role in the oxidation of sorafenib to its $N$-oxide and $N$-hydroxymethyl metabolites and also acts in concert with CYP2C8 to mediate imatinib $N$-demethylation. CYP3A4 expression and function are impaired in patients with advanced liver disease, whereas the functions of CYP2C enzymes are relatively preserved. We evaluated the biotransformation of sorafenib and imatinib in well-characterized microsomal fractions from 17 control subjects and 19 individuals with hepatic cirrhosis of varying severity. The principal findings were that liver disease impaired the microsomal oxidation of sorafenib to its major metabolites to 40$44 \%$ of control $(\mathrm{P}<0.01)$, whereas the $N$-demethylation of imatinib was relatively unimpaired. The impairments in sorafenib biotransformation were correlated with decreased serum albumin concentrations and increased serum bilirubin concentrations in patients with liver disease, but not with the overall grade of liver disease according to the Child-Pugh system. In contrast, there was no relationship between imatinib $N$-demethylation and clinicopathologic factors in liver disease patients. These findings were accounted for in terms of the differential roles of CYPs 3A4 and 2C8 in the intrinsic clearance of the drugs. CYP3A4 has the major role in the intrinsic clearance of sorafenib but plays a secondary role to CYP2C8 in the intrinsic clearance of imatinib. In agreement with these findings CYP2C protein expression and CYP2C8mediated paclitaxel $6 \alpha$-hydroxylation were unimpaired in cirrhotic livers. This information could be adapted in individualized approaches such as in vivo CYP3A4 phenotyping to optimize sorafenib safety and efficacy in cancer patients with liver dysfunction.

Keywords: sorafenib biotransformation, imatinib biotransformation, CYP3A4, CYP2C8, hepatic cirrhosis 
Chemical compounds studied in this article: Sorafenib (PubChem CID: 216239), imatinib (PubChem CID: 5291), midazolam (PubChem CID: 4192), paclitaxel (PubChem CID: 36314), tolbutamide (PubChem CID: 5505), dextromethorphan (PubChem CID: 5360696). 


\section{Introduction}

Tyrosine kinase inhibitors (TKIs) are a recently-developed class of targeted oncology drugs that have significantly improved the treatment of patients with a range of tumors. Sorafenib and imatinib are two important TKIs that are used in the treatment of liver and renal clear cell carcinomas and chronic myelogenous leukemia and gastrointestinal stromal tumors, respectively. Sorafenib targets the Raf kinase, vascular endothelial growth factor receptor and platelet derived growth factor receptor, while imatinib targets the TKs bcr-abl and c-kit (Demetri et al., 2002; Druker et al., 1996; Liu et al., 2006). However, although these agents are generally well tolerated, imatinib and sorafenib produce a range of toxicities in certain patients, including hypertension, edema or major dermal toxicities such as the hand-foot syndrome (Escudier et al., 2007; Ugurel et al., 2003). Such adverse effects may lead to the interruption or termination of TKI therapy.

The aim of personalized medicine is to tailor drug selection and dosage to the individual patient. Biotransformation enzymes, especially the hepatic cytochrome P450 (CYP) mixedfunction oxidases, are major factors that influence the rate of drug elimination. Individuals in whom CYP oxidation capacity is high may clear drugs rapidly, which can result in treatment failure because therapeutic serum concentrations are not maintained, while low CYP oxidation may result in drug accumulation and toxicity at standard doses of drugs. Recent studies have demonstrated roles for the quantitatively important human hepatic CYP3A and CYP2C enzymes in the oxidation of the TKIs sorafenib and imatinib (Dutreix et al., 2004; Ghassabian et al., 2012; Lathia et al., 2006; Nebot et al., 2010).

Liver disease impairs CYP expression directly, which can decrease intrinsic drug clearance $\left(\mathrm{CL}_{\mathrm{int}}\right)$, or indirectly as a result of pathophysiological changes that alter hepatic blood flow and the perfusion of hepatocytes. Hepatic cirrhosis is a major form of end-stage liver disease that is characterized by increased fibrotic infiltration and destruction of the hepatic 
architecture (Johnson et al., 2010). The obstruction of blood flow promotes portal hypertension as well as the development of portacaval shunts, ascites and gastrointestinal bleeding. Predictions of the effects of advanced liver disease on the biotransformation of drugs such as TKIs are of potential importance in the design of safer dosage regimen in patients (Johnson et al., 2010).

Clinical studies have indicated that the clearance of drugs that are substrates for CYP3A4, such as midazolam and erythromycin, is markedly decreased in advanced liver disease (Barre et al., 1987; Chalasani et al., 2001). Analogous biochemical studies have shown that the oxidative biotransformation of CYP3A4 substrates is impaired because the enzyme is down-regulated in liver disease (George et al., 1995; Guengerich and Turvy, 1991). The available information on alterations in CYP2C protein expression in patients with liver disease is more variable. As summarized by Johnson et al. (2010), the expression of CYP2C protein and activity ranged from unchanged in one study to $34-72 \%$ of control in two others. However, a likely contributing factor to this variation is the use of polyclonal antibodies that were unable to discriminate between CYP2C subfamily members. The use of monospecific antibodies and selective drug substrates may provide more detailed information on the impact of liver disease on individual CYPs $2 \mathrm{C}$.

The biotransformation of TKIs like sorafenib and imatinib that are metabolized by CYP3A could complicate the treatment of cancer patients with hepatic dysfunction. Accordingly, the present study evaluated the biotransformation of these TKIs in wellcharacterized hepatic microsomal fractions from patients with cirrhotic liver disease, compared with control. The principal finding to emerge was that the dysregulation of CYP3A4 in cirrhosis markedly decreased sorafenib biotransformation, whereas imatinib oxidation, which also involves a significant contribution from the CYP2C8 enzyme, was relatively preserved. 
These findings may assist the design of dosage modification approaches in patients with liver disease and who receive TKIs that have a high dependence on CYP3A4 for clearance. 


\section{Materials and Methods}

\subsection{Drugs and Chemicals}

Sorafenib (4-[4-([4-chloro-3-(trifluoromethyl)phenyl]carbamoylamino)phenoxy]- $N$ methylpyridine-2-carboxamide) and its $N$-oxide and $N$-hydroxymethyl metabolites were synthesized as described previously (Gillani et al., 2015). Imatinib mesylate ((4-[(4methylpiperazin-1-yl)methyl]- $N$-[4-methyl-3-[(4-pyridin-3-ylpyrimidin-2-

yl)amino]phenyl]benzamide)), $N$-desmethylimatinib and imatinib- $d_{8}$ (internal standard) were gifts from Novartis (Basel, Switzerland). Midazolam, dextromethorphan, dextrorphan, and all biochemicals were obtained from Sigma-Aldrich (Castle Hill, NSW, Australia). Sorafenibmethyl- $d_{3}$ and $6 \alpha$-hydroxypaclitaxel were purchased from Toronto Research Chemicals (North York, ON, Canada) and 1'-hydroxymidazolam was from Cerilliant (Round Rock, TX, USA). HPLC grade solvents were from LabScan (Lomb Scientific, Taren Point, NSW, Australia), and analytical grade reagents were from Ajax Chemicals (Sydney, NSW, Australia).

\subsection{Liver donors and preparation of microsomal fractions}

Experiments with human liver microsomes were approved by ethics committees of the Western Sydney Area Health Service and the University of Sydney, according to the Declaration of Helsinki. Liver tissue from 36 individual donors was obtained through the Queensland and Australian Liver Transplant Programs (Princess Alexandria Hospital, Brisbane, Queensland, and Royal Prince Alfred Hospital, Sydney, NSW, Australia, respectively). "Control" human liver was obtained as excess tissue during transplantation or as biopsies from the normal margin during resection of liver tumours. Cirrhotic tissue was obtained from individuals in whom the presence of ascites, hepatic encephalopathy and sepsis was recorded by the attending physician. The severity of liver disease was graded according to the Child-Pugh system which is calculated from the clinical assessment of ascites, 
encephalopathy, serum albumin and bilirubin concentrations, and prothrombin time. Each variable is graded between 1 and 3 based on the extent of impairment. The total Child-Pugh score ranges from 5 to 15 , where 5 indicates that there is no hepatic decompensation and where 15 indicates severe liver failure (Christensen et al., 1984). The nutritional status of patients in the present study was assessed as normal, impaired or cachectic, based on the extent of muscle bulk and subcutaneous fat. Drug histories were collected where information was available.

In patients, venous blood samples were withdrawn after an overnight fast and used to determine serum bilirubin and albumin concentrations and prothrombin times. Blood was centrifuged and stored at $-70^{\circ} \mathrm{C}$ until subjected to automated analysis (Department of Clinical Chemistry, Westmead Hospital, Westmead, NSW, Australia).

Liver tissue was obtained from the superior surface of the right lobe within $0.25 \mathrm{~h}$ of surgical removal, perfused with cold Viaspan solution (DuPont, Wilmington, DE, USA), snap frozen in liquid nitrogen and stored at $-70^{\circ} \mathrm{C}$. Liver microsomes were prepared by ultracentrifugation and stored at $-70^{\circ} \mathrm{C}$ in potassium phosphate buffer $(0.05 \mathrm{M}, \mathrm{pH} 7.4$, containing $1 \mathrm{mM}$ EDTA and 20\% glycerol; Murray et al., 1985). Microsomal protein content was determined as described previously (Marcus et al., 1985).

\subsection{Drug biotransformation by human liver microsomes}

In all assays of drug biotransformation the linearity of product formation in incubations was established in relation to microsomal protein, substrate concentration and incubation time. Substrate concentrations were 2-11-fold of reported $\mathrm{K}_{\mathrm{m}}$, with the exception of the low-affinity substrate tolbutamide, which was studied around the $\mathrm{K}_{\mathrm{m}}$. To ensure enzyme saturation the substrate utilization was limited to $<15 \%$ in all cases.

Microsomal sorafenib biotranformation was determined as described previously (Ghassabian et al., 2012). Briefly, incubations (75 $\mu \mathrm{g}$ microsomal protein, $75 \mu \mathrm{M}$ sorafenib) 
in $0.1 \mathrm{M}$ potassium phosphate buffer $(\mathrm{pH} 7.4,0.25 \mathrm{~mL})$ at $37^{\circ} \mathrm{C}$ were initiated using NADPH $(1 \mathrm{mM})$. Reactions were terminated after $20 \mathrm{~min}$ with cold acetonitrile $(0.5 \mathrm{~mL})$, the precipitate was removed by centrifugation and the supernatant was dried under a stream of nitrogen gas; the internal standard was sorafenib-methyl- $d_{3}$. Sorafenib and its metabolites were quantified on a Thermo Scientific TSQ Quantum Access Max liquid chromatography-tandem mass spectrometry (LC-MS/MS) system using electrospray ionization (positive ion mode; San Jose, CA, USA) with separation on a Waters XTerra MS C18 3.5 $\mu$ column (150 x 2.1 mm I.D.; Waters, Rydalmere, NSW, Australia).

Microsomal imatinib biotranformation was determined as described previously (Nebot et al., 2010). Briefly, incubations (150 $\mu \mathrm{g}$ microsomal protein, $80 \mu \mathrm{M}$ imatinib) in $0.1 \mathrm{M}$ potassium phosphate buffer $(\mathrm{pH} 7.4,0.2 \mathrm{~mL})$ at $37^{\circ} \mathrm{C}$ were initiated with NADPH $(1 \mathrm{mM})$. Reactions were terminated after 10 min with $5 \%$ trifluoroacetic acid $(5 \mu \mathrm{L})$ and applied to Varian Bond Elut Plexa solid-phase extraction cartridges $(1 \mathrm{~mL})$. Cartridges were eluted with methanol ( $3 \times 1.25 \mathrm{~mL}$ aliquots) which was then evaporated to dryness; the internal standard was imatinib- $d_{8}$. Imatinib and $N$-desmethylimatinib were quantified on a Finnigan MAT TSQ 7000 LC-MS/MS system using electrospray ionization (positive ion mode; San Jose, CA, USA) with separation on an Altima C18 $5 \mu$ column (150 x $2.1 \mathrm{~mm}$ I.D.; Alltech Associates, Castle Hill, NSW, Australia).

CYP3A-mediated midazolam 1'-hydroxylation was determined as described previously (Ghassabian et al., 2009). Incubations (100 $\mu \mathrm{g}$ microsomal protein, $5 \mu \mathrm{M}$ midazolam) in $0.1 \mathrm{M}$ potassium phosphate buffer $(\mathrm{pH} 7.4,0.5 \mathrm{~mL})$ at $37^{\circ} \mathrm{C}$ were initiated by NADPH $(1 \mathrm{mM})$. Reactions were terminated after 5 min with cold $0.1 \%$ formic acid $(1.5 \mathrm{~mL})$ and applied to Bond Elut C18 SPE cartridges (Agilent Technologies, Mulgrave, VIC, Australia). After washing with ammonium acetate $(10 \mathrm{mM}, 1 \mathrm{~mL})$ cartridges were eluted with methanol ( 2 x $1 \mathrm{~mL})$; the internal standard was diazepam. Midazolam and its 1'-hydroxy- 
metabolite were separated on a Finnigan MAT TSQ 7000 LC-MS/MS system using electrospray ionization (positive ion mode) with separation on an Altima C18 5 $\mu$ column (150 x $2.1 \mathrm{~mm}$ I.D.).

CYP2C8-mediated paclitaxel 6 $\alpha$-hydroxylation activity was determined as described previously (Vaclavikova et al., 2003). Incubations (150 $\mu \mathrm{g}$ microsomal protein, $25 \mu \mathrm{M}$ paclitaxel) in $0.1 \mathrm{M}$ potassium phosphate buffer $(\mathrm{pH} 7.4,0.5 \mathrm{~mL})$ at $37^{\circ} \mathrm{C}$ were initiated with NADPH (1 mM). Reactions were terminated after 90 min with cold acetonitrile $(1 \mathrm{~mL})$ and the organic layer was evaporated under nitrogen; the internal standard was timolol. After reconstitution with mobile phase (20 mM ammonium acetate: acetonitrile: methanol, 5:3:2; 0.1 $\mathrm{mL})$ extracts were subjected to HPLC analysis on a Finepak SIL C18-5 column (15 cm x 4.6 mm I.D.; JASCO, Meadowbank, NSW, Australia) with UV detection (227 nm).

CYP2C9-mediated tolbutamide methylhydroxylation activity was determined as described previously (Murray et al., 1994). Incubations (200 $\mu \mathrm{g}$ microsomal protein, $150 \mu \mathrm{M}$ tolbutamide) in $0.1 \mathrm{M}$ potassium phosphate buffer $(\mathrm{pH} 7.4,0.5 \mathrm{~mL})$ at $37^{\circ} \mathrm{C}$ were initiated with NADPH $(1 \mathrm{mM})$. Reactions were terminated after 15 min with cold $\mathrm{HCl}(7.5 \mathrm{M}, 20 \mu \mathrm{L})$, extracted with diethyl ether ( 2 x $1 \mathrm{~mL})$ and the organic layer was evaporated under nitrogen; the internal standard was chlorpropamide. Extracts were reconstituted with mobile phase (acetonitrile: $0.05 \%$ phosphoric acid, $3: 7 ; 0.4 \mathrm{~mL}$ ) and subjected to HPLC analysis on an Inertsil ODS-2 column (5 $\mu 15$ cm x 4.6 mm I.D.; GL Science, Tokyo, Japan) with UV detection $(230 \mathrm{~nm})$.

CYP2D6-mediated dextromethorphan $O$-demethylation activity was determined as described previously (Ghassabian et al., 2009). Incubations (150 $\mu \mathrm{g}$ microsomal protein, 16 $\mu \mathrm{M}$ dextromethorphan) in potassium phosphate buffer $(0.1 \mathrm{M}, \mathrm{pH} 7.4)$ at $37^{\circ} \mathrm{C}$ were initiated with NADPH (1 mM). Reactions were terminated after 30 min with ice-cold buffer and loaded onto Oasis HLB solid-phase cartridges (Waters Associates, Rydalmere, NSW, Australia). 
Cartridges were washed with $10 \%$ aqueous methanol $(2 \times 1 \mathrm{~mL})$ and then eluted with methanol $(2 \times 1 \mathrm{~mL})$; the internal standard was phenacetin. Dextromethorphan and dextrorphan were separated on a Finnigan MAT TSQ 7000 LC-MS/MS system using electrospray ionization (positive ion mode) with separation on an Altima C18 $5 \mu$ column (150 x $2.1 \mathrm{~mm}$ I.D.).

\section{$2.4 \quad$ Immunoquantification of microsomal proteins}

Hepatic microsomal protein $(10 \mu \mathrm{g}$ for CYP3A4, $5 \mu \mathrm{g}$ for CYP3A5, $10 \mu \mathrm{g}$ for CYP2C and $25 \mu \mathrm{g}$ protein for CYP2D6) was resolved on $10 \%$ sodium dodecyl sulfate-polyacrylamide gels $(2 \mathrm{~h}$ at $120 \mathrm{~V})$, transferred electrophoretically to Protran nitrocellulose (Schleicher and Schuell, Dassel, Germany) and then subjected to Western immunoblot analysis as described previously (Stupans et al., 2001). Monospecific rabbit antibodies directed against peptides that corresponded to the C-terminal regions of human CYP2C8, CYP2D6, CYP3A4 and CYP3A5 were prepared as described by Edwards et al. (1998). Immunoreactive proteins were detected by enhanced chemiluminescence (GE Healthcare, Chalfont St. Giles, UK) on Hyperfilm-ECL (Amersham, Little Chalfont, UK) and the resultant signals were analyzed by densitometry (Bio-Rad, Richmond, CA). Signal intensity was linear under these conditions.

\subsection{Statistical analyses}

Data are expressed throughout as means \pm S.E.M. Differences between activities in control and liver disease samples were detected using the unpaired two-tailed Student's t-test after log transformation (Statview; Abacus concepts, Berkeley, CA, USA). P values $<0.05$ were accepted as statistically significant. 


\section{Results}

\subsection{Clinicopathologic factors and drug histories in patients who donated liver tissue}

Of the 36 patients who provided liver tissue seventeen were classed as controls because there was no evidence of liver disease, as defined by nutritional status, ascites or hepatic encephalopathy; nineteen patients had liver disease of varying severity (Table 1). Five of the liver disease patients were diagnosed with autoimmune chronic active hepatitis, four had primary biliary cirrhosis and three had primary biliary sclerosing cholangitis. Of the remaining liver disease patients one each had alcoholic liver disease, $\alpha_{1}$-antitrypsin deficiency, idiopathic cirrhosis, Budd-Chiari syndrome, hepatitis $\mathrm{C}$ and biliary atresia, while a further patient was diagnosed with coincident alcoholic liver disease and $\alpha_{1}$-antitrypsin deficiency. Nutritional status was impaired in four of the liver disease patients and seven had cachexia. In three patients mild ascites was present, moderate ascites was present in another and four patients exhibited severe ascites. Three patients exhibited severe hepatic encephalopathy while in another hepatic encephalopathy was less pronounced. One patient presented with sepsis and another had a secondary diagnosis of diabetes mellitus. Taken together, eleven patients were assessed as having the most severe liver dysfunction in cirrhosis (Child-Pugh class C), seven were ChildPugh class B and one was Child-Pugh class A.

All of the liver disease patients received concurrent medications (Table 1). The most commonly prescribed agents were diuretics (spironolactone and frusemide), anti-infectives (norfloxacin, cefotaxime, ciprofloxacin and rifampicin), $\mathrm{H}_{2}$-receptor antagonists (ranitidine, omeprazole and cimetidine), $\beta$-receptor antagonists (propranolol and atenolol), analgesics (pethidine, paracetamol and codeine) and glucucorticoids (prednisone and hydrocortisone). Some patients also received oxazepam, sucralfate, insulin and thyroxine. 
Drug histories were also available for eight of the control liver donors. Drugs used in these patients included cephalothin, metronidazole, $\alpha$-methyldopa, colloidal bismuth subcitrate, sucralfate, oxazepam and simvastatin (one instance each; not shown).

Information from liver function tests was available for all of the patients with liver disease and eight of the controls. As shown in Fig 1 serum albumin concentrations were decreased in donors with liver disease $(29 \pm 1 \mathrm{mg} / \mathrm{mL}$, range $23-41 \mathrm{mg} / \mathrm{mL}$, compared to $42 \pm 1$ $\mathrm{mg} / \mathrm{mL}$ in control; $\mathrm{p}<0.001$; the normal range is $\sim 36-55 \mathrm{mg} / \mathrm{mL}$ ). Serum bilirubin concentrations were increased in cirrhotic patients $(137 \pm 32 \mu \mathrm{M}$, range $18-488 \mu \mathrm{M}$, compared to normal concentrations of $\leq 20 \mu \mathrm{M} ; \mathrm{p}<0.05)$ and prothrombin time was prolonged $(27 \pm 3 \mathrm{sec}$, range 12-60 sec, compared to normal $\leq 14 \mathrm{sec} ; \mathrm{p}<0.05$ ).
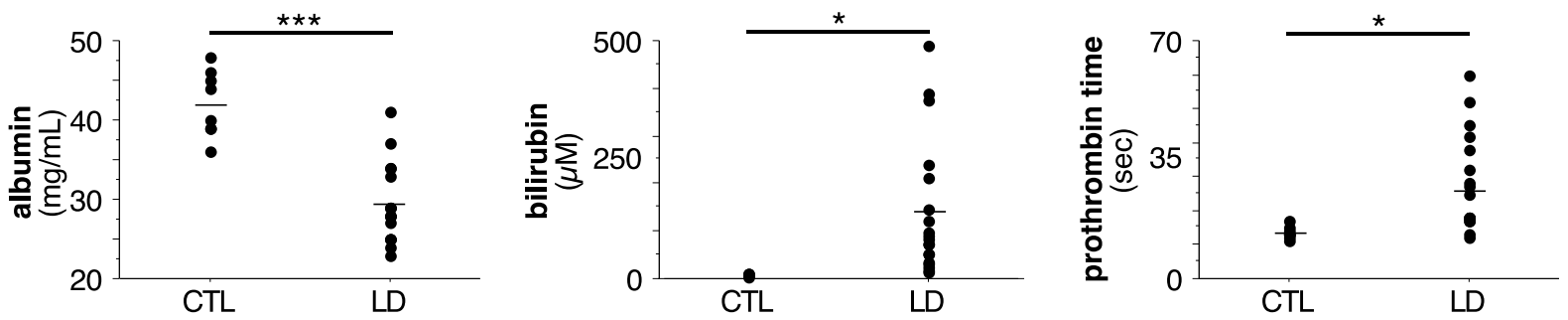

Figure 1:Serum albumin and bilirubin concentrations and prothrombin times in patients with liver disease (LD) compared with control (CTL) subjects. Different from control: $* \mathrm{P}<0.05$, $* * * \mathrm{P}<0.001$. Horizontal bars indicate data means. 


\section{Table 1}

Clinicopathological characteristics of liver disease patients ${ }^{\mathrm{a}, \mathrm{b}}$

\begin{tabular}{|c|c|c|c|c|c|c|}
\hline $\begin{array}{l}\text { Patient } \\
\text { (arbitrary } \\
\text { number) }\end{array}$ & diagnosis & $\begin{array}{l}\text { nutritional } \\
\text { status } \\
(\text { score })^{\mathrm{c}}\end{array}$ & $\begin{array}{l}\text { ascites } \\
\text { (score) }\end{array}$ & $\begin{array}{c}\text { hepatic } \\
\text { encephalopathy } \\
\text { (score) }\end{array}$ & $\begin{array}{c}\text { Child-Pugh } \\
\text { grade }\end{array}$ & Drugs \\
\hline 1 & alcoholic liver disease, $\alpha 1$-antitrypsin deficiency & 3 & 3 & 0 & $\mathrm{C}$ & NOR, RAN, OXA \\
\hline 2 & $\alpha 1$-antitrypsin deficiency & 2 & 2 & 0 & $\mathrm{~B}$ & OXA, SPI, OME \\
\hline 3 & idiopathic cirrhosis without cholestasis & 3 & 0 & 0 & $\mathrm{~B}$ & SPI, SUC \\
\hline 4 & autoimmune chronic active hepatitis & 1 & 2 & 0 & $\mathrm{C}$ & SPI, PRE \\
\hline 5 & autoimmune chronic active hepatitis & 1 & 0 & 2 & $\mathrm{C}$ & PRE \\
\hline 6 & Budd Chiari syndrome & 3 & 1 & 0 & $\mathrm{C}$ & RAN, CEF, PRO, PET, HYD \\
\hline 7 & autoimmune chronic active hepatitis ${ }^{\mathrm{d}}$ & 3 & 3 & 0 & $\mathrm{C}$ & RAN, PRE, INS \\
\hline 8 & alcoholic liver disease & 1 & 0 & 0 & B & SPI, PRO, FRU, CIM \\
\hline 9 & autoimmune chronic active hepatitis & 1 & 0 & 0 & $\mathrm{~B}$ & NOR, SPI, PRE, PRO \\
\hline
\end{tabular}




\begin{tabular}{|c|c|c|c|c|c|c|}
\hline 10 & autoimmune chronic active hepatitis & 1 & 0 & 1 & A & PRE \\
\hline 11 & hepatitis C & 2 & 1 & 0 & $\mathrm{C}$ & SPI, CIP \\
\hline 12 & primary biliary cirrhosis & 2 & 0 & 0 & $\mathrm{C}$ & NOR, SPI \\
\hline 13 & primary sclerosing cholangitis & 1 & 0 & 0 & $\mathrm{~B}$ & CIP \\
\hline 14 & primary biliary cirrhosis & 3 & 0 & 0 & $\mathrm{C}$ & SPI, ATE \\
\hline 15 & biliary atresia and idiopathic intrahepatic cholestasis & 3 & 0 & 0 & $\mathrm{~B}$ & SPI, RIF \\
\hline 16 & primary sclerosing cholangitis ${ }^{\mathrm{e}}$ & 2 & 1 & 0 & $\mathrm{C}$ & $\mathrm{CEF}$ \\
\hline 17 & primary biliary cirrhosis & 1 & 0 & 2 & $\mathrm{C}$ & RAN, SPI, FRU \\
\hline 18 & primary sclerosing cholangitis & 3 & 0 & 0 & $\mathrm{~B}$ & RAN, PAR, COD \\
\hline 19 & primary biliary cirrhosis $^{f}$ & 1 & 0 & 2 & $\mathrm{C}$ & SPI, THY \\
\hline
\end{tabular}

Demographic factors: age range 0-66 years, ${ }^{\mathrm{b}} \mathrm{M}: \mathrm{F} 7: 12$.

${ }^{\mathrm{c}}$ Score: nutritional status: 1 normal, 2 impaired, 3 cachexia; ascites: 0 nil, 1 mild, 2 moderate, 3 severe; hepatic encephalopathy: 0 (none)-2;

Overall Child-Pugh grade A, B or C.

${ }^{\mathrm{d}}$ Co-diagnosis: diabetes mellitus.

${ }^{\mathrm{e}}$ Sepsis. 
${ }^{\mathrm{f}}$ Smoker (>5 cigarettes/day).

Concurrent drugs: NOR, norfloxacin; RAN, ranitidine; OXA, oxazepam; SPI, spironolactone; OME, omeprazole; SUC, sucralfate; PRE, prednisone; CEF, cefotaxime; PRO, propranolol; PET, pethidine; HYD, hydrocortisone; INS, insulin; FRU, frusemide; CIM, cimetidine; CIP, ciprofloxacin; ATE, atenolol; RIF, rifampicin; PAR, paracetamol; COD, codeine; THY, thyroxine. 
3.2 Impact of liver disease on TKI biotransformation and CYP expression

A
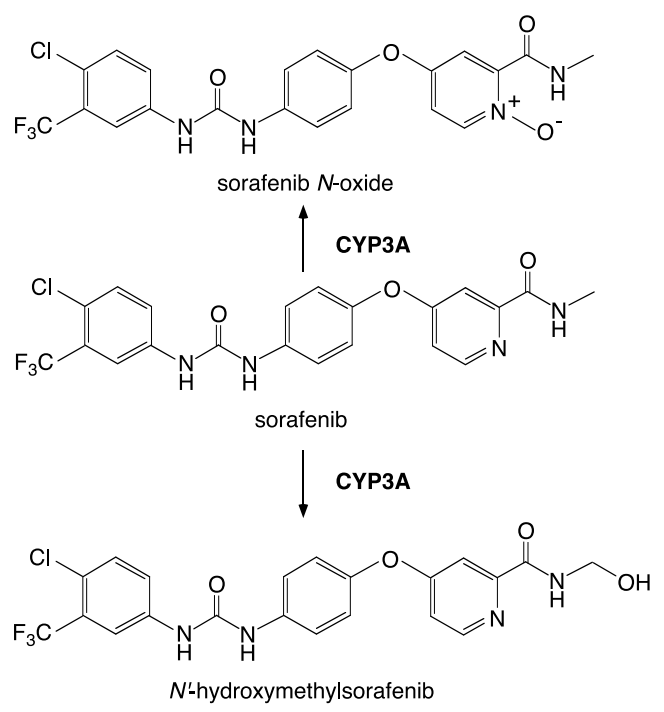

B

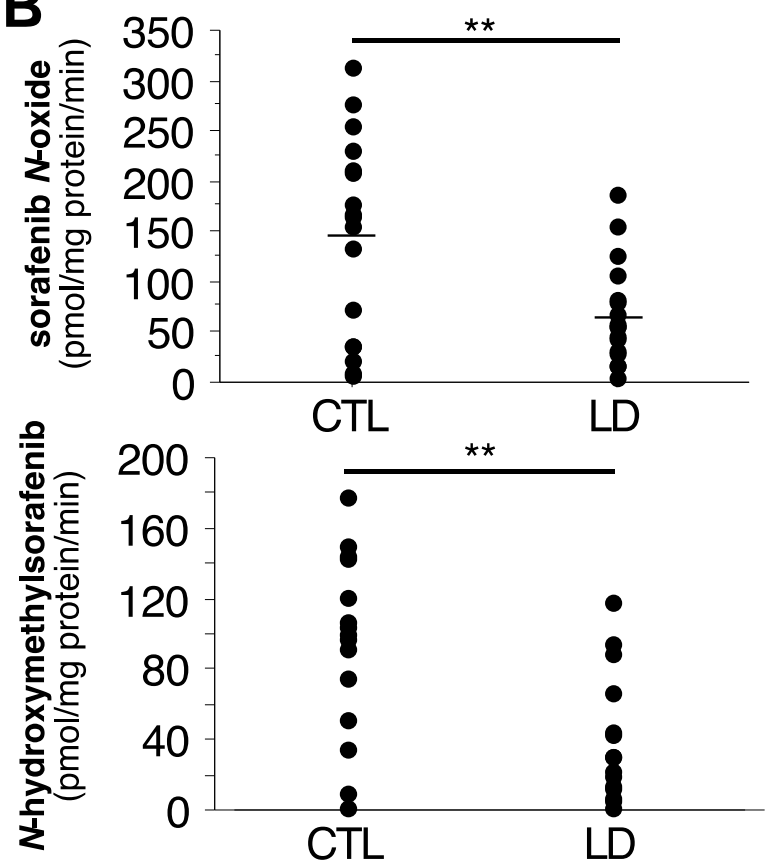

Figure 2: (A) Biotransformation of sorafenib to its N-oxide and N-hydroxymethyl metabolites, (B) rates of sorafenib $\mathrm{N}$-oxide and $\mathrm{N}$-hydroxymethylsorafenib formation in microsomal fractions from control (CTL) and liver disease (LD) patients. Different from control: $* * \mathrm{P}<0.01$. Horizontal bars indicate data means.

Sorafenib was oxidized to two major metabolites in human liver microsomes: sorafenib $N$-oxide and $N$-hydroxymethylsorafenib (Fig 2A). Sorafenib $N$-oxide formation was lower in microsomes from patients with liver disease to $44 \pm 8 \%$ of that in control liver fractions $(64 \pm 12$ $\mathrm{pmol} / \mathrm{mg}$ protein/min; range $1-187 \mathrm{pmol} / \mathrm{mg}$ protein/min, versus $146 \pm 24 \mathrm{pmol} / \mathrm{mg}$ protein/min in control, range 7-312 pmol/mg protein/min; P<0.01; Fig 2B). Similarly, $N$-hydroxymethyl sorafenib formation was lower in microsomes from patients with liver disease to $40 \pm 10 \%$ of control (33 $\pm 9 \mathrm{pmol} / \mathrm{mg}$ protein $/ \mathrm{min}$, range $0-118 \mathrm{pmol} / \mathrm{mg}$ protein $/ \mathrm{min}$ versus $83 \pm 14 \mathrm{pmol} / \mathrm{mg}$ protein/min in control, range $0-177 \mathrm{pmol} / \mathrm{mg}$ protein/min; $\mathrm{P}<0.01$; Fig $2 \mathrm{~B}$ ). Because CYP3A has a major role in the biotransformation of sorafenib we also measured CYP3A-dependent 
midazolam 1'-hydroxylation in microsomal fractions. The activity was lower in microsomes from patients with liver disease to $61 \pm 8 \%$ of control $(0.22 \pm 0.03 \mathrm{nmol} / \mathrm{mg}$ protein $/ \mathrm{min}$ compared with $0.36 \pm 0.04 \mathrm{nmol} / \mathrm{mg}$ protein/min in control; $\mathrm{p}<0.01$; Fig $3 \mathrm{~A}$ ). In accord with these findings, CYP3A4 protein expression was lower in liver disease fractions $(47 \pm 13 \%$ of control; $\mathrm{P}<0.05$ ), but expression of the closely related CYP3A5 was not impaired (Fig 4).

A

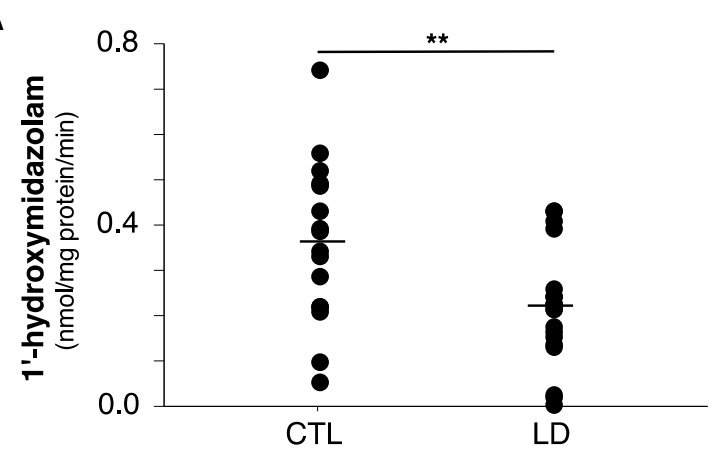

C

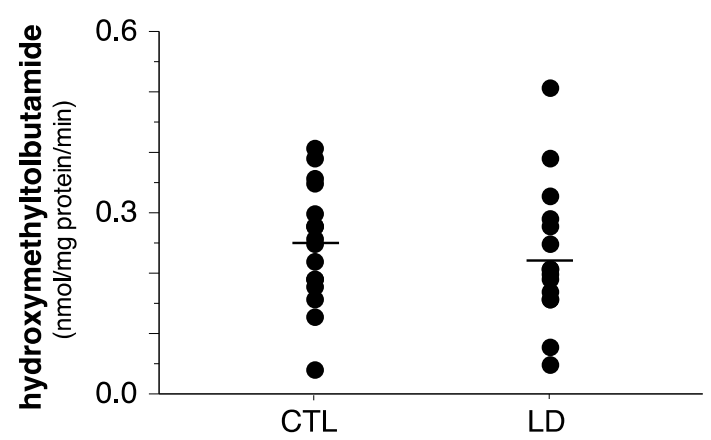

B

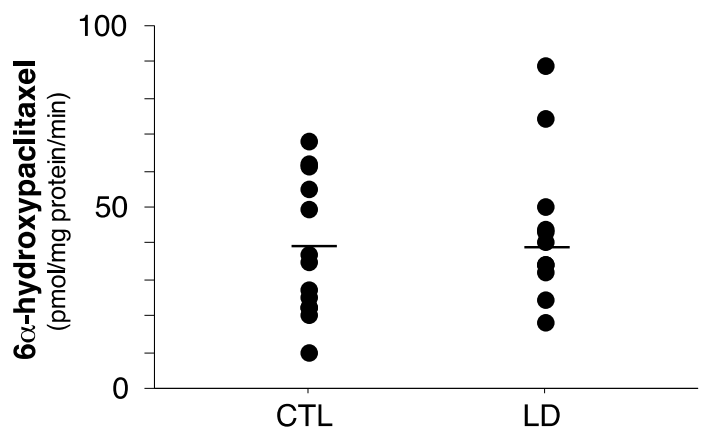

D

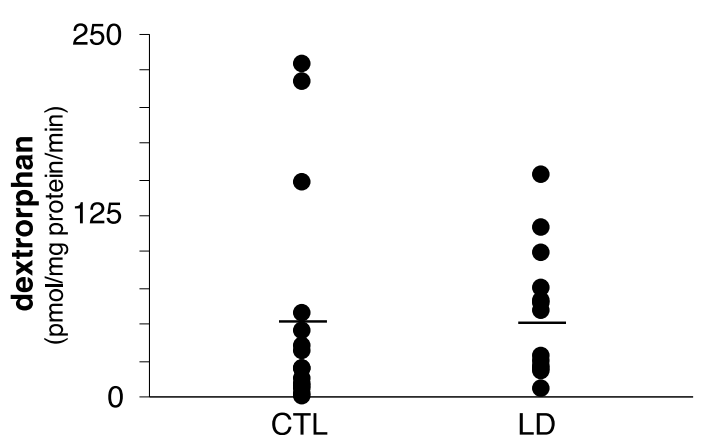

Figure 3: Rates of (A) CYP3A-mediated midazolam 1'-hydroxylation (B) CYP2C8mediated paclitaxel 6 $\alpha$-hydroxylation (C) CYP2C9-mediated tolbutamide methylhydroxylation and (D) CYP2D6-mediated dextromethorphan O-demethylation in control (CTL) and liver disease (LD) microsomal fractions. Different from control: $* * \mathrm{P}<0.01$ Horizontal bars indicate data means. 
In this study we also assessed whether liver disease altered the microsomal oxidation of another major TKI imatinib. However, in contrast to sorafenib biotransformation, imatinib $\mathrm{N}$-demethylation was not significantly lower in microsomal fractions from patients with hepatic cirrhosis $(18 \pm 3 \mathrm{pmol} / \mathrm{mg}$ protein $/ \mathrm{min}$; range $6.8-63 \mathrm{pmol} / \mathrm{mg}$ protein $/ \mathrm{min}$ versus $22 \pm 3$ $\mathrm{pmol} / \mathrm{mg}$ protein/min in control; range $6.3-35 \mathrm{pmol} / \mathrm{mg}$ protein $/ \mathrm{min}$; Fig 5). Because both CYP3A and CYP2C8 have been shown to participate in imatinib $N$-demethylation we measured CYP2C8-mediated paclitaxel 6 $\alpha$-hydroxylation in microsomal fractions. It was found that liver disease did not alter paclitaxel $6 \alpha$-hydroxylation significantly $(37 \pm 7 \mathrm{pmol} / \mathrm{mg}$ protein/min; range $0-89 \mathrm{pmol} / \mathrm{mg}$ protein $/ \mathrm{min}$ in liver disease versus $37 \pm 5 \mathrm{pmol} / \mathrm{mg}$ protein/min; range 10-68 $\mathrm{pmol} / \mathrm{mg}$ protein/min in control; Fig 3B). To further evaluate the impact of liver disease on CYPs 2C we measured the activity of the closely related CYP2C9, as reflected by tolbutamide methylhydroxylation. The activity was also unchanged in samples from patients with liver disease $(0.22 \pm 0.03 \mathrm{nmol} / \mathrm{mg}$ protein $/ \mathrm{min}$; range $0-0.51 \mathrm{nmol} / \mathrm{mg}$ protein $/ \mathrm{min}$ in liver disease versus $0.25 \pm 0.03 \mathrm{nmol} / \mathrm{mg}$ protein $/ \mathrm{min}$; range $0.04-0.41 \mathrm{nmol} / \mathrm{mg}$ protein/min in control; Fig 3C). In comparison, CYP2D6-mediated dextromethorphan $O$ demethylation was unchanged in microsomes from patients with liver disease $(53 \pm 11 \mathrm{pmol} / \mathrm{mg}$ protein/min; range $0-155 \mathrm{pmol} / \mathrm{mg}$ protein/min versus $54 \pm 19 \mathrm{pmol} / \mathrm{mg}$ protein $/ \mathrm{min}$; range 0 $231 \mathrm{pmol} / \mathrm{mg}$ protein/min in control; Fig 3D). In accordance with these findings total immunoreactive CYP2C and CYP2D6 proteins were not significantly lower in cirrhotic liver than in control liver (Fig 4). These findings suggest that, of the CYPs evaluated in the present study, CYP3A4 is selectively decreased in liver disease, and that this leads to different effects on the oxidative biotransformation of the TKIs sorafenib and imatinib. CYPs 2C and CYP2D6 are relatively preserved. 

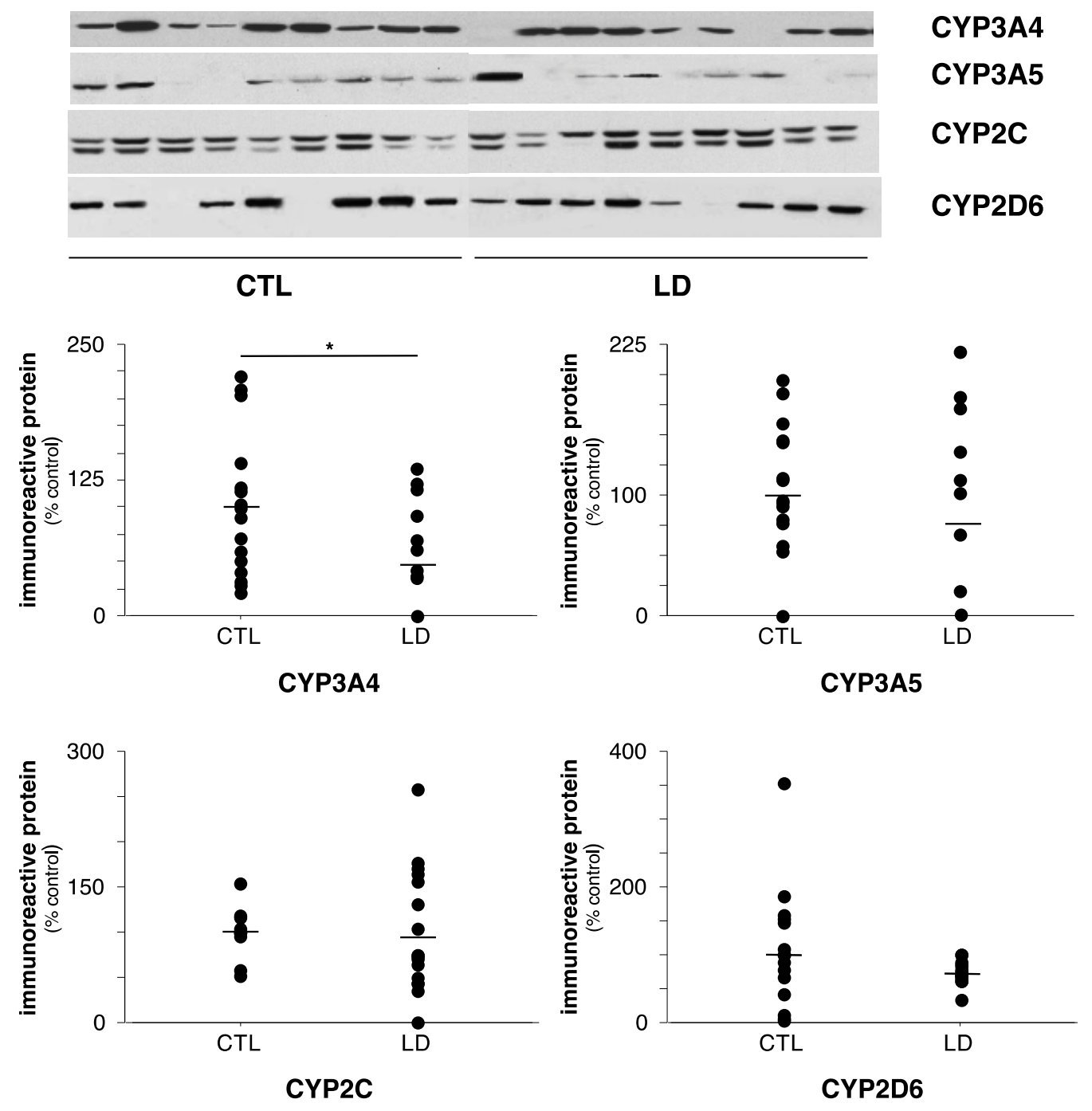

Figure 4: Immunoreactive CYP3A4, CYP3A5, CYP2C and CYP2D6 expression in microsomal fractions from control (CTL) subjects and patients with liver disease (LD). Immunoblots in nine representative CTL and LD microsomal fractions are shown. Different from control: $* \mathrm{P}<0.05$. Horizontal bars indicate data means. 


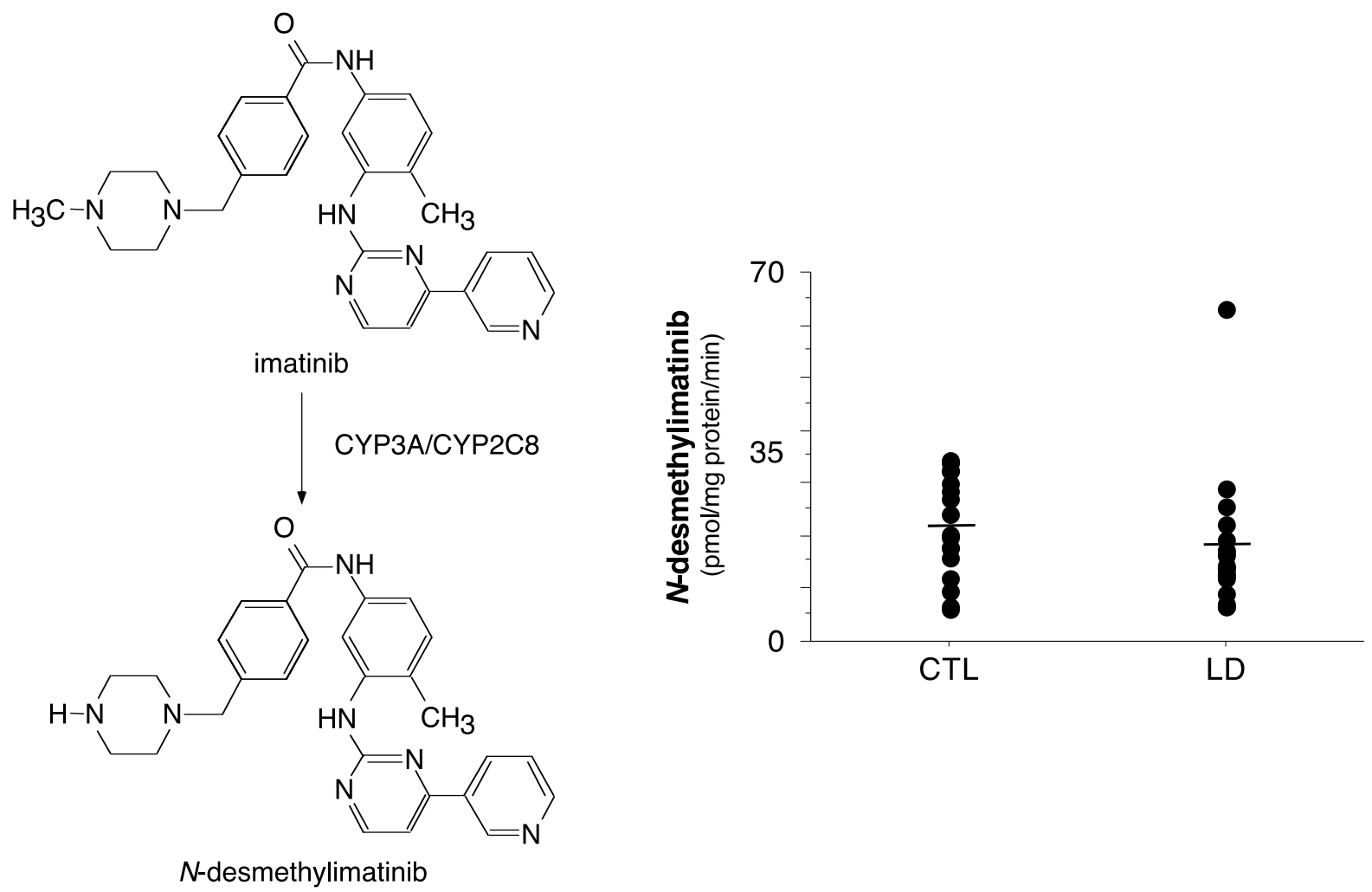

Figure 5: Biotransformation of imatinib to its N-desmethyl metabolite in microsomal fractions from control (CTL) and liver disease (LD) patients. Horizontal bars indicate data means.

\subsection{Relationship of liver dysfunction to CYP biotransformation capacity}

The relationships between clinicopathological factors in patients that relate to liver function, and the formation of major metabolites of sorafenib and imatinib were assessed. As shown in Figure 6A the formation of both sorafenib $\mathrm{N}$-oxide and $\mathrm{N}$-hydroxymethylsorafenib was positively correlated with serum albumin $(\mathrm{r}=0.68$ in both cases, $\mathrm{P}<0.001)$ and negatively correlated with serum bilirubin concentrations ( $\mathrm{r}=-0.57$ and -0.58 , respectively, $\mathrm{P}<0.01) . \mathrm{N}$ Hydroxymethylsorafenib formation was also negatively correlated to prothrombin time ( $\mathrm{r}=-$ $0.44, \mathrm{p}<0.05)$, whereas the relationship with sorafenib $N$-oxide formation was not significant (r=-0.34). In contrast, imatinib $N$-demethylation was inversely correlated with serum bilirubin concentrations $(\mathrm{r}=-0.42, \mathrm{P}<0.05)$ but not serum albumin concentrations or prothrombin time 
(not shown). We assessed whether the extent of impairment in sorafenib biotransformation was related to the Child-Pugh grade of the donor patients. However, as shown in Fig 6B, there was no clear relationship between the severity of liver disease, according to the Child-Pugh system, and the decreased microsomal production of major sorafenib metabolites.

A
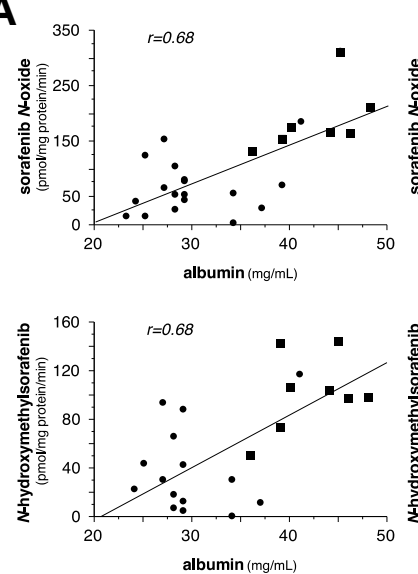
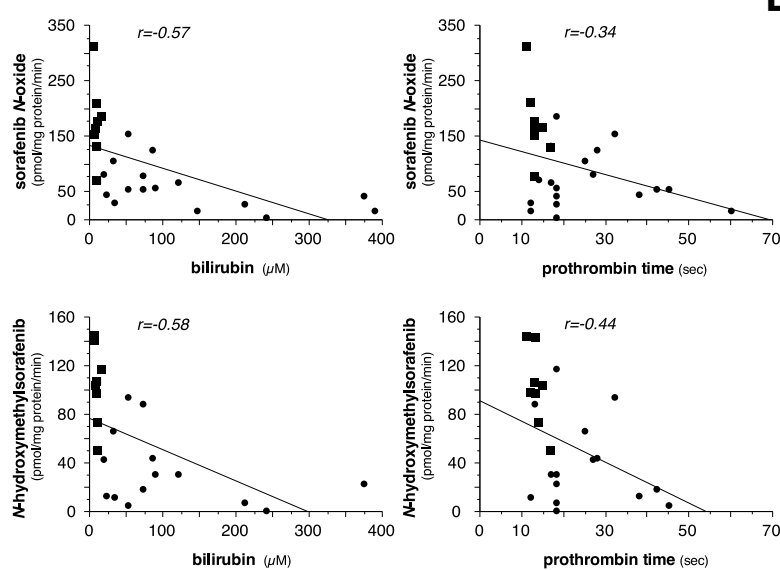

B

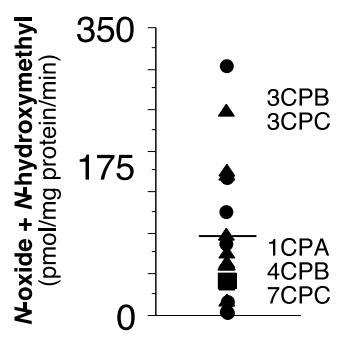

Figure 6: (A) Regression analysis of the relationships between sorafenib N-oxide and Nhydroxymethylsorafenib formation and serum albumin concentrations, serum bilirubin concentrations and prothrombin times in control (squares) and liver disease (circles) patients. (B) Sorafenib metabolite formation (sum of N-oxide and N-hydroxymethyl) metabolites in microsomal fractions from patients with liver disease of varying Child-Pugh grade. The patient samples of each Child-Pugh grade that are above and below the mean value (horizontal bar) are shown. 


\section{Discussion}

TKIs such as sorafenib and imatinib are well tolerated in most subjects but some patients experience toxicity that necessitate dose reduction or cessation. Knowledge of clearance pathways is required for the development of personalized approaches to optimize therapy based on drug pharmacokinetics. Recent work has established that CYP3A4 and CYP3A5 are important catalysts in the formation of major sorafenib metabolites and that these enzymes act in conjunction with CYP2C8 in the $N$-demethylation of imatinib.

To avoid drug toxicity careful dosing is important in patients with liver disease because pathophysiological changes directly alter the clearance of drugs (Franz et al., 2013). Decreased functional liver mass, decreased CYP biotransformation enzymes, altered plasma protein binding and altered hepatic blood flow each exert differential effects on drug clearance (Johnson et al., 2010); only the unbound fraction of drug is cleared. For drugs that are highly extracted by the liver, altered liver blood flow has the major effect on rates of systemic clearance, whereas low extraction drugs are more dependent on rates of intrinsic hepatic clearance. Sorafenib and imatinib are low hepatic extraction drugs that are highly protein bound ( 99\% and 95\%, respectively). Accordingly, liver disease is likely to influence their clearance by decreasing intrinsic clearance and possibly also by decreasing the synthesis of albumin, which could modulate unbound drug concentrations.

In liver disease the impairment of systemic drug clearance is related to the particular drug. The clearances of CYP3A substrates, midazolam, nifedipine and erythromycin are lower in patients with severe liver disease (Barre et al., 1987; Chalasani et al., 2001; Ene and Roberts, 1987). Thus, Johnson et al. (2010) proposed that an understanding of the role of CYP3A and other biotransformation enzymes in clearance is essential to begin to design modified dosage regimen. In the present study CYP3A4-dependent oxidation of the TKI sorafenib was lower in microsomes from patients with chronic liver disease, consistent with the decline in CYP3A4 
expression and function in these fractions. In contrast, imatinib $N$-demethylation was relatively preserved in microsomes from patients with severe liver disease. Because CYP2C8 is an important contributor to the activity we evaluated this finding further and noted that CYP2C8mediated paclitaxel $6 \alpha$-hydroxylation and CYP2C protein were not impaired in the fractions from patients with liver disease. This is consistent with clinical reports that the impact of liver disease on the clearance of CYP2C drug substrates is less pronounced than on the clearance of CYP3A substrate drugs (Villeneuve and Pichette, 2004; Johnson et al., 2010). More recently, CYP2C8 expression and function was also found to be essentially unaltered during the progression of human non-alcoholic fatty liver disease, which is a form of liver injury that can precede the development of more advanced disease (Fisher et al., 2009; Rong et al., 2010).

Because sorafenib and imatinib are low hepatic extraction drugs we considered the roles of CYPs in their CLint. From measurements in cDNA-expressed CYPs the catalytic efficiencies of CYP3A4 and CYP3A5 in sorafenib $N$-oxidation were found previously to be 9.4 and 0.74 $\mathrm{pmol} / \mathrm{pmol} \mathrm{CYP} / \mathrm{h} / \mu \mathrm{M}$, respectively, and 4.5 and $0.8 \mathrm{pmol} / \mathrm{pmol} \mathrm{CYP} / \mathrm{h} / \mu \mathrm{M}$, respectively, in $N$-hydroxymethylsorafenib formation (Ghassabian et al., 2012). In the case of imatinib $N$ demethylation the catalytic efficiencies of CYP2C8, CYP3A4 and CYP3A5 were reported to be 17.5, 1.2 and $1.0 \mathrm{pmol} / \mathrm{pmol} \mathrm{CYP} / \mathrm{h} / \mu \mathrm{M}$, respectively (Nebot et al., 2010). Thus, the relative contribution of CYP2C8 to imatinib $N$-demethylation is $\sim 15$-fold of that of CYP3A4. Recent estimates of CYP3A4 content in human liver are in the range $0-350 \mathrm{pmol} / \mathrm{mg}$ microsomal protein (Huang et al., 2004; Naraharisetti et al., 2010) while CYP2C8 is in the range 0-90 pmol/mg microsomal protein (Bahadur et al., 2002; Naraharisetti et al., 2010; RodriguezAntona et al., 2008). Thus, the mean expression of CYP2C8 protein is $\sim 0.25$-fold of that of CYP3A4. CYP3A5 is absent from many livers because an intron polymorphism introduces an mRNA splicing defect that prevents the translation of CYP3A5 protein (Huang et al., 2004; Lin et al., 2002). Adaptation of this information suggests that the relative contribution of 
CYP2C8 to the $\mathrm{CL}_{\text {int }}$ of imatinib is $~ 3.6$-fold that of CYP3A4 (17.5/1.2 x 0.25). Taken together these findings suggest that the major role of CYP3A4 in the $\mathrm{CL}_{\text {int }}$ of sorafenib is responsible for the loss of oxidation capacity. In contrast, CYP2C8 activity was not markedly lower in liver disease, which could facilitate the relative preservation of imatinib $N$-demethylation.

The pharmacokinetic behaviour of sorafenib and imatinib is complex and exhibits wide inter-individual variation (Minami et al., 2008; Strumberg et al., 2007; Widemann et al., 2012); this complicates dose determination. The area under the serum concentration versus time curve (AUC) values for both sorafenib and imatinib were altered over time in patients who received fixed doses (Boudou-Rouquette et al., 2012; Judson et al., 2005). Compared to AUC data after one day of treatment, both drugs accumulated at steady state and showed increased AUC values that then declined after prolonged treatment (Boudou-Rouquette et al., 2012; Eechoute et al., 2012; Furuse et al., 2008; Peng et al., 2004).

There have been clinical reports that the pharmacokinetics of sorafenib may be complicated in some patients with liver disease, which could have consequences for safety (Arrondeau et al., 2012; Abou alfa et al., 2006; Fukudo et al., 2014; Miller et al., 2009; Shimada et al., 2015). Earlier studies reported no differences in pharmacokinetics in patients with mild-moderate liver dysfunction (Child-Pugh grade A or B), although inter-patient variation was high (Abou alfa et al., 2006). However, although single dose sorafenib produced similar AUC values in patients with a range of liver disease severities, toxicity was observed in patient cohorts with more severe liver dysfunction, even at lower doses (Miller et al., 2009). To date, there have been few studies of sorafenib pharmacokinetics in patients with the highest grade of liver dysfunction (Child-Pugh grade C disease) (Fukudo et al., 2014; Kane et al., 2009). Indeed, such studies are impractical in patients with severe liver dysfunction who require significant dose reductions to tolerate the drug (some can tolerate only $200 \mathrm{mg}$ every 
third day compared with $400 \mathrm{mg}$ twice daily in patients with normal liver function; Miller et al., 2009).

The pharmacokinetics and tolerability of imatinib appear to be unchanged in patients with impaired liver function. A study of two patients with GIST with impaired liver function reported normal responses to standard doses of imatinib over 3-4 months of therapy with no increase in toxicity (Bauer et al., 2005). Two larger studies reported that imatinib was effective in patients with concurrent liver dysfunction and CML (Tong et al., 2010) or a range of malignancies (Ramanathan et al., 2008). Moreover, despite large inter-patient variability, the plasma pharmacokinetics and urinary excretion of imatinib did not differ between patients with normal function and liver dysfunction (Ramanathan et al., 2008). The current consensus appears to be that imatinib can be safely administered at the recommended dose provided liver function is closely monitored (Judson, 2008; Eckel et al., 2005).

The microsomal fractions used in this study were prepared from "control" liver donated by subjects without hepatic dysfunction and 19 individuals with impaired liver function, 18 of whom were either Child-Pugh grade B or C. Regulatory agencies have prepared guidance documents for drug evaluations in patients with impaired liver function that relate drug clearance to the Child-Pugh grade and suggest that pharmacokinetic studies are warranted if biotransformation represents $\geq 20 \%$ of overall elimination or if the drugs have narrow therapeutic indices (USFDA, 2003). There are several limitations to the Child-Pugh system, which was not originally devised as a tool to assess drug metabolizing capacity. It performs best in patients with decompensated end-stage severe liver disease but otherwise lacks discriminatory power. In addition, the constituent variables are influenced by factors other than liver dysfunction (Zgheib and Branch, 2017). Whether serum concentrations of albumin or bilirubin, or other endogenous parameters, such as serum cholesterol, may be more reliable indicators of altered TKI drug clearance in liver dysfunction remains to be fully explored, but 
there is evidence that they may have some utility. As mentioned, sorafenib is highly bound to serum albumin and a decrease in hepatic albumin production has been found to alter sorafenib clearance in cancer patients (Tod et al., 2011). Furthermore, Miller et al., (2009) found that higher bilirubin concentrations were associated with lower AUCs for sorafenib $N$-oxide in patient cohorts with diminished liver function. However, in the present study microsomal TKI biotransformation was only partially correlated with serum albumin and bilirubin concentrations. Taken together, it is probably unlikely that such parameters will be useful for dose personalization in patients with liver disease because they are insensitive indicators of drug oxidation capacity. Instead, the present findings suggest that longitudinal monitoring of serum levels of sorafenib (Shimada et al., 2015) or in vivo CYP3A4 phenotyping using the erythromycin breath test or midazolam clearance, might better predict clearance in individual patients (Ghassabian et al., 2009; Ramanathan et al., 2008).

\section{Conclusion}

In the present study clinical parameters relating to liver function were correlated with the biotransformation of sorafenib, as well as to the CYP3A substrate midazolam, but not to the biotransformation of imatinib. These findings were attributed to the differential effects of liver disease on CYP3A4 and CYP2C8 that have major roles in the $\mathrm{CL}_{\text {int }}$ of sorafenib and imatinib, respectively. The overall Child-Pugh grade, which has been used to determine dosage modifications for potentially toxic drugs in patients with liver disease, was not closely related to CYP3A function or sorafenib biotransformation. The lack of discriminatory power and specificity of the Child-Pugh system are limitations to its use in the assessment of drug clearance by the liver (Zgheib and Branch, 2017). Accordingly, more direct measures of sorafenib elimination in patients, such as therapeutic monitoring or in vivo phenotyping for 
CYP3A4 could be warranted to enable dose determination protocols to be developed for some TKI drugs (Ghassabian et al., 2009; Ramanathan et al., 2008). 


\section{Conflicts of interest}

None

\section{Acknowledgements}

The authors gratefully acknowledge financial support from Cancer Council NSW (grants RG09-14 and IG11-33). Technical contributions in aspects of the study from Dr S. Cui, Ms K Bourget, Mr E Li and Ms L Pharm are also acknowledged. The supply of several of the human liver samples used in this study by Dr J George is also gratefully acknowledged. 


\section{References}

Abou-Alfa, G.K., Schwartz, L., Ricci, S., Amadori, D., Santoro, A., Figer, A., De Greve, J., Douillard, J.Y., Lathia, C., Schwartz, B., Taylor, I., Moscovici, M., Saltz, L.B., 2006. Phase II study of sorafenib in patients with advanced hepatocellular carcinoma. J. Clin. Oncol. 24, 4293-4300.

Arrondeau, J., Mir, O., Boudou-Rouquette, P., Coriat, R., Ropert, S., Dumas, G., Rodrigues, M.J., Rousseau, B., Blanchet, B., Goldwasser, F., 2012. Sorafenib exposure decreases over time in patients with hepatocellular carcinoma. Investig. New Drugs 30, 2046-2049.

Bahadur, N., Leathart, J.B., Mutch, E., Steimel-Crespi, D., Dunn, S.A., Gilissen, R., Houdt, J.V., Hendrickx, J., Mannens, G., Bohets, H., Williams, F.M., Armstrong, M., Crespi, C.L., Daly, A.K., 2002. CYP2C8 polymorphisms in Caucasians and their relationship with paclitaxel 6 $\alpha$-hydroxylase activity in human liver microsomes. Biochem. Pharmacol. 64, 1579-1589.

Barre, J., Mallat, A., Rosenbaum, J., Deforges, L., Houin, G., Dhumeaux, D., Tillement, J.P., 1987. Pharmacokinetics of erythromycin in patients with severe cirrhosis. Respective influence of decreased serum binding and impaired liver metabolic capacity. Br. J. Clin. Pharmacol. 23, 753-757.

Bauer, S., Hagen, V., Pielken, H.J., Bojko, P., Seeber, S., Schutte, J., 2002. Imatinib mesylate therapy in patients with gastrointestinal stromal tumors and impaired liver function. Anticancer drugs $13,847-849$.

Boudou-Rouquette, P., Ropert, S., Mir, O., Coriat, R., Billemont, B., Tod, M., Cabanes, L., Franck, N., Blanchet, B., Goldwasser, F., 2012. Variability of sorafenib toxicity and exposure over time: a pharmacokinetic/pharmacodynamic analysis. Oncologist 17, 12041212. 
Chalasani, N., Gorski, J.C., Patel, N.H., Hall, S.D., Galinsky, R.E., 2001. Hepatic and intestinal cytochrome P450 3A activity in cirrhosis: effects of transjugular intrahepatic portosystemic shunts. Hepatology 34, 1103-1108.

Christensen, E., Schlichting, P., Fauerholdt, L., Gluud, C., Andersen, P.K., Juhl, E., Poulsen, H., Tygstrup, N., 1984. Prognostic value of Child-Turcotte criteria in medically treated cirrhosis. Hepatology 4, 430-435.

Demetri, G.D., von Mehren, M., Blanke, C.D., Van den Abbeele, A.D., Eisenberg, B., Roberts, P.J., Heinrich, M.C., Tuveson, D.A., Singer, S., Janicek, M., Fletcher, J.A., Silverman, S.G., Silberman, S.L., Capdeville, R., Kiese, B., Peng, B., Dimitrijevic, S., Druker, B.J., Corless, C., Fletcher, C.D., Joensuu, H., 2002. Efficacy and safety of imatinib mesylate in advanced gastrointestinal stromal tumors. N. Engl. J. Med. 347, 472-480.

Druker, B.J., Tamura, S., Buchdunger, E., Ohno, S., Segal, G.M., Fanning, S., Zimmermann, J., Lydon, N.B., 1996. Effects of a selective inhibitor of the Abl tyrosine kinase on the growth of Bcr-Abl positive cells. Nature Med. 2, 561-566.

Dutreix, C., Peng, B., Mehring, G., Hayes, M., Capdeville, R., Pokorny, R., Seiberling, M., 2004. Pharmacokinetic interaction between ketoconazole and imatinib mesylate (Glivec) in healthy subjects. Cancer Chemother. Pharmacol. 54, 290-294.

Eckel, F., von Delius, S., Mayr, M., Dobritz, M, Fend, F., Hosius, C., Schleyer, E., SchulteFrohlinde, E., Schmid, R.M., Lersch, C., 2005. Pharmacokinetic and clinical phase II trial of imatinib in patients with impaired liver function and advanced hepatocellular carcinoma. Oncology 69, 363-371.

Edwards, R.J., Adams, D.A., Watts, P.S., Davies, D.S., Boobis, A.R., 1998. Development of a comprehensive panel of antibodies against the major xenobiotic metabolising forms of cytochrome P450 in humans. Biochem. Pharmacol. 56, 377-387. 
Eechoute, K., Fransson, M.N., Reyners, A.K., de Jong, F.A., Sparreboom, A., van der Graaf, W.T., Friberg, L.E., Schiavon, G., Wiemer, E.A., Verweij, J., Loos, W.J., Mathijssen, R.H., De Giorgi, U., 2012. A long-term prospective population pharmacokinetic study on imatinib plasma concentrations in GIST patients. Clin. Cancer Res. 18, 5780-5787.

Ene, M.D., Roberts, C.J., 1987. Pharmacokinetics of nifedipine after oral administration in chronic liver disease. J. Clin. Pharmacol. 27, 1001-1004.

Escudier, B., Eisen, T., Stadler, W.M., Szczylik, C., Oudard, S., Siebels, M., Negrier, S., Chevreau, C., Solska, E., Desai, A.A., Rolland, F., Demkow, T., Hutson, T.E., Gore, M., Freeman, S., Schwartz, B., Shan, M., Simantov, R., Bukowski, R.M., 2007. TARGET Study Group. Sorafenib in advanced clear-cell renal-cell carcinoma. N. Engl. J. Med. $356,125-134$.

Fisher, C.D., Lickteig, A.J., Augustine, L.M., Ranger-Moore, J., Jackson, J.P., Ferguson, S.S., Cherrington, N.J., 2009. Hepatic cytochrome P450 enzyme alterations in humans with progressive stages of nonalcoholic fatty liver disease. Drug Metab. Dispos 37, 20872094.

Franz, C.C., Hildbrand, C., Born, C., Egger, S., Rätz Bravo, A.E., Krähenbühl, S., 2013. Dose adjustment in patients with liver cirrhosis: impact on adverse drug reactions and hospitalizations. Eur. J. Clin. Pharmacol. 69, 1565-1573.

Fukudo, M., Ito, T., Mizuno, T., Shinsako, K., Hatano, E., Uemoto, S., Kamba, T., Yamasaki, T., Ogawa, O., Seno, H., Chiba, T., Matsubara, K., 2014. Exposure-toxicity relationship of sorafenib in Japanese patients with renal cell carcinoma and hepatocellular carcinoma. Clin. Pharmacokinet. 53, 185-196.

Furuse, J., Ishii, H., Nakachi, K., Suzuki, E., Shimizu, S., Nakajima, K., 2008. Phase I study of sorafenib in Japanese patients with hepatocellular carcinoma. Cancer Sci. 99, 159-165. 
George, J., Murray, M., Byth, K., Farrell, G.C., 1995. Differential alterations of cytochrome P450 proteins in livers from patients with severe chronic liver disease. Hepatology 21, $120-128$.

Ghassabian, S., Chetty, M., Tattam, B.N., Glen, J., Rahme, J., Stankovic, Z., Ramzan, I., Murray, M., McLachlan, A.J., 2009. A high-throughput assay using liquid chromatography/tandem mass spectrometry for simultaneous in vivo phenotyping of five major cytochrome P450 enzymes in patients. Ther. Drug Monit. 31, 239-246.

Ghassabian, S., Rawling, T., Zhou, F., Doddareddy, M.R., Tattam, B.N., Hibbs, D.E., Edwards, R.J., Cui, P.H., Murray, M., 2012. Role of human CYP3A4 in the biotransformation of sorafenib to its major oxidized metabolites. Biochem. Pharmacol. 84, 215-223.

Gillani, T., Rawling, T., Murray, M., 2015. Cytochrome P450-mediated biotransformation of sorafenib and its $N$-oxide metabolite: implications for cell viability and human toxicity. Chem. Res. Toxicol. 28, 92-102.

Guengerich, F.P., Turvy, C.G., (1991). Comparison of levels of several human microsomal cytochrome P-450 enzymes and epoxide hydrolase in normal and disease states using immunochemical analysis of surgical liver samples. J. Pharmacol. Exp. Ther. 256: 11891194.

Huang, W., Lin, Y.S., McConn, D.J., 2nd, Calamia, J.C., Totah, R.A., Isoherranen, N., Glodowski, M., Thummel, K.E., 2004. Evidence of significant contribution from CYP3A5 to hepatic drug metabolism. Drug Metab. Dispos. 32: 1434-1445.

Johnson, T.N., Boussery, K., Rowland-Yeo, K., Tucker, GT., Rostami-Hodjegan, A., 2010. A semi-mechanistic model to predict the effects of liver cirrhosis on drug clearance. Clin. Pharmacokinet. 49: 189-206.

Judson, I., Ma, P., Peng, B., Verweij, J., Racine, A., di Paola, E.D., van Glabbeke, M., Dimitrijevic, S., Scurr, M., Dumez, H., van Oosterom, A., 2005. Imatinib 
pharmacokinetics in patients with gastrointestinal stromal tumour: a retrospective population pharmacokinetic study over time. EORTC Soft Tissue and Bone Sarcoma Group. Cancer Chemother. Pharmacol. 55: 379-386.

Judson, I.R., 2008. Imatinib for patients with liver or kidney dysfunction: no need to modify the dose. J. Clin. Oncol. 26, 521-522.

Kane, R.C., Farrell, A.T., Madabushi, R., Booth, B., Chattopadhyay, S., Sridhara, R., Justice, R., Pazdur, R., 2009. Sorafenib for the treatment of unresectable hepatocellular carcinoma. Oncologist 14, 95-100.

Lathia, C., Lettieri, J., Cihon, F., Gallentine, M., Radtke, M., Sundaresan, P., 2006. Lack of effect of ketoconazole-mediated CYP3A inhibition on sorafenib clinical pharmacokinetics. Cancer Chemother. Pharmacol. 57, 685-692.

Lin, Y.S., Dowling, A.L., Quigley, S.D., Farin, F.M., Zhang, J., Lamba, J., Schuetz, E.G., Thummel, K.E., 2002. Co-regulation of CYP3A4 and CYP3A5 and contribution to hepatic and intestinal midazolam metabolism. Mol. Pharmacol. 62, 162-172.

Liu, L., Cao, Y., Chen, C., Zhang, X., McNabola, A., Wilkie, D., Wilhelm, S., Lynch, M., Carter, C., 2006. Sorafenib blocks the RAF/MEK/ERK pathway, inhibits tumor angiogenesis, and induces tumor cell apoptosis in hepatocellular carcinoma model PLC/PRF/5. Cancer Res. 66, 11851-11858.

Marcus, C.B., Murray, M., Wilkinson, C.F. 1985. Spectral and inhibitory interactions of methylenedioxyphenyl and related compounds with purified isozymes of cytochrome P450. Xenobiotica 15, 351-362.

Miller, A.A., Murry, D.J., Owzar, K., Hollis, D.R., Kennedy, E.B., Abou-Alfa, G., Desai, A., Hwang, J., Villalona-Calero, M.A., Dees, E.C., Lewis, L.D., Fakih, M.G., Edelman, M.J., Millard, F., Frank, R.C., Hohl, R.J., Ratain, M.J., 2009. Phase I and pharmacokinetic 
study of sorafenib in patients with hepatic or renal dysfunction: CALGB 60301. J. Clin. Oncol. 27, 1800-1805.

Minami, H., Kawada, K., Ebi, H., Kitagawa, K., Kim, Y.I., Araki, K., Mukai, H., Tahara, M., Nakajima, H., Nakajima, K., 2008. Phase I and pharmacokinetic study of sorafenib, an oral multikinase inhibitor, in Japanese patients with advanced refractory solid tumors. Cancer Sci. 99, 1492-1498.

Murray, M., Butler, A.M., Stupans, I., 1994. Competitive inhibition of human liver microsomal P450 3A-dependent steroid 6 $\beta$-hydroxylation activity by cyclophosphamide and ifosfamide in vitro. J. Pharmacol. Exp. Ther. 270, 645-649.

Murray, M., Hetnarski, K., Wilkinson, C.F., 1985. Selective inhibitory interactions of alkoxymethylenedioxybenzenes towards monooxygenase activity in rat hepatic microsomes. Xenobiotica 15, 369-379.

Naraharisetti, S.B., Lin. Y.S., Rieder, M.J., Marciante, K.D., Psaty, B.M., Thummel, K.E., Totah, R.A., 2010. Human liver expression of CYP2C8: gender, age, and genotype effects. Drug Metab. Dispos. 38, 889-893.

Nebot, N., Crettol, S., d'Esposito, F., Tattam, B., Hibbs, D.E., Murray, M., 2010. Participation of CYP2C8 and CYP3A4 in the $N$-demethylation of imatinib in human hepatic microsomes. Br. J. Pharmacol. 161, 1059-1069.

Peng, B., Hayes, M., Resta, D., Racine-Poon, A., Druker, B.J., Talpaz, M., Sawyers, C.L., Rosamilia, M., Ford, J., Lloyd, P., Capdeville, R., 2004. Pharmacokinetics and pharmacodynamics of imatinib in a phase I trial with chronic myeloid leukemia patients. J. Clin. Oncol. 22, 935-942.

Ramanathan, R.K., Egorin, M.J., Takimoto, C.H., Remick, S.C., Doroshow, J.H., LoRusso, P.A., Mulkerin, D.L., Grem, J.L., Hamilton, A., Murgo, A.J., Potter, D.M., Belani, C.P., Hayes, M.J., Peng, B., Ivy, S.P., National Cancer Institute Organ Dysfunction Working 
Group., 2008. Phase I and pharmacokinetic study of imatinib mesylate in patients with advanced malignancies and varying degrees of liver dysfunction: a study by the National Cancer Institute Organ Dysfunction Working Group. J. Clin. Oncol. 26, 563-569.

Rodríguez-Antona, C., Niemi. M., Backman, J.T., Kajosaari, L.I., Neuvonen, P.J., Robledo, M., Ingelman-Sundberg, M., 2008. Characterization of novel CYP2C8 haplotypes and their contribution to paclitaxel and repaglinide metabolism. Pharmacogenom. J. 8, 268277.

Rong, X., Li, Y., Ebihara, K., Zhao, M., Naowaboot, J., Kusakabe, T., Kuwahara, K., Murray, M., Nakao, K., 2010. Angiotensin II type 1 receptor-independent beneficial effects of telmisartan on dietary-induced obesity, insulin resistance and fatty liver in mice. Diabetologia 53, 1727-1731.

Shimada, M., Okawa, H., Kondo, Y., Maejima, T., Kataoka, Y., Hisamichi, K., Maekawa, M., Matsuura, M., Jin, Y., Mori, M., Suzuki, H., Shimosegawa, T., Mano, N., 2015. Monitoring serum levels of sorafenib and its N-oxide is essential for long-term sorafenib treatment of patients with hepatocellular carcinoma. Tohoku J. Exp. Med. 237, 173-182.

Strumberg, D., Clark, J.W., Awada, A., Moore, M.J., Richly, H., Hendlisz, A., Hirte, H.W., Eder, J.P., Lenz, H.J., Schwartz, B., 2007. Safety, pharmacokinetics, and preliminary antitumor activity of sorafenib: a review of four phase I trials in patients with advanced refractory solid tumors. Oncologist 12, 426-437.

Stupans, I., Murray, M., Kirlich, A., Tuck, K., Hayball, P., 2001. Inactivation of cytochrome P450 by the food-derived complex phenol oleuropein. Food Chem. Toxicol. 39, 11191124.

Tod, M., Mir, O., Bancelin, N., Coriat, R., Thomas-Schoemann, A., Taieb, F., BoudouRouquette, P., Ropert, S., Michels, J., Abbas, H., Durand, J.P., Dauphin, A., Vidal, M., Goldwasser, F., Blanchet, B., 2011. Functional and clinical evidence of the influence of 
sorafenib binding to albumin on sorafenib disposition in adult cancer patients. Pharm Res 28, 3199-2307.

Tong, W.G., Kantarjian, H., O'Brien, S., Faderl, S., Ravandi, F., Borthakur, G., Shan, J., Pierce, S., Rios, M.B., Cortes, J., 2010. Imatinib front-line therapy is safe and effective in patients with chronic myelogenous leukemia with pre-existing liver and/or renal dysfunction. Cancer 116, 3152-3159.

Ugurel, S., Hildenbrand, R., Dippel, E., Hochhaus, A., Schadendorf, D., 2003. Dose-dependent severe cutaneous reactions to imatinib. Br. J. Cancer 88, 1157-1159.

USFDA, US Food and Drug Administration., 2003. Guidance for industry. Pharmacokinetics in patients with impaired hepatic function: study design, data analysis, and impact on $\begin{array}{llll}\text { dosing and } & \text { labeling. }\end{array}$ (http://www.fda.gov/downloads/drugs/guidancecomplianceregulatoryinformation/guida nces/ucm072123.pdf), accessed June 14, 2017.

Vaclavikova, R., Soucek, P., Svobodova, L., Anzenbacher, P., Simek, P., Guengerich, F.P., Gut, I., 2003. Different in vitro metabolism of paclitaxel and docetaxel in humans, rats, pigs and minipigs. Drug Metab. Dispos. 32, 666-674.

Villeneuve, J.P., Pichette, V., 2004. Cytochrome P450 and liver diseases. Curr. Drug Metab. $5,273-282$.

Widemann, B.C., Kim, A., Fox, E., Baruchel, S., Adamson, P.C., Ingle, A.M., Glade Bender, J., Burke, M., Weigel, B., Stempak, D., Balis, F.M., Blaney, S.M., 2012. A phase I trial and pharmacokinetic study of sorafenib in children with refractory solid tumors or leukemias: a Children's Oncology Group Phase I Consortium report. Clin. Cancer Res. $18,6011-6022$.

Zgheib, N.K., Branch, R.A. 2017. Drug metabolism and liver disease: a drug-geneenvironment interaction. Drug Metab. Rev. 49, 35-55. 
